\title{
Anti-Insurance: Analysing the Health Insurance System in Australia *
}

\author{
Joshua S. Gans and Stephen P. King \\ Melbourne Business School \\ and
}

Melbourne Institute of Applied Economic and Social Research

The University of Melbourne

\author{
Melbourne Institute Working Paper No. 10/03 \\ ISSN 1328-4991 (Print) \\ ISSN 1447-5863 (Online) \\ ISBN 073403122 X
}

April 2003

\begin{abstract}
* We would like to thank Ian Harper, Rhema Vaithianathan and participants at the 2003 Australian Theory Workshop for valuable input into this research. We also thank Medibank Private Ltd for financial assistance. Responsibility for all views and omissions lies with the authors and not with any of the above individuals or organisations. Corresponding author: Stephen King, s.king@mbs.edu.
\end{abstract}

Melbourne Institute of Applied Economic and Social Research

The University of Melbourne

Victoria 3010 Australia

Telephone (03) 83443701

Fax (03) 83445630

Email melb-inst@unimelb.edu.au

WWW Address http://www.melbourneinstitute.com 


\begin{abstract}
This paper develops a model to analyse the Australian health insurance system when individuals differ in their health risk and this risk is private information. The Australian system involves mixed public and private health insurance with private insurance both duplicating and supplementing public insurance. We show that, absent any other interventions, the Australian system implicitly transfers wealth from those most at risk of adverse health to those least at risk. When considered over society as a whole, these transfers represent a mean preserving spread of income, creating social risk and lowering welfare. We refer to these implicit transfers as anti-insurance. Further, we use comparative statics to show that a decline in the take-up of private insurance may lead to a reduction in the welfare of all members of society. Increased take-up of private health insurance may be Pareto improving.

We consider the recently introduced rebate on private health insurance and show that this alleviates this welfare reducing anti-insurance. However, its ad valorem nature distorts insurance premiums. We demonstrate that a lump sum rebate could achieve the same reduction in anti-insurance while avoiding additional dead weight losses. Nonetheless, we conclude by suggesting that more significant reform of the Australian system is needed, for example by moving to a system of supplementary private health insurance.
\end{abstract}




\section{Introduction}

Australia has a mixed system of public and private health insurance. Public health insurance coverage is not means tested and private health insurance 'overlaps' with public insurance. In other words, an individual or family that take out private health insurance may use that insurance to pay for medical expenditures that would otherwise be covered by public health insurance as well as using the private insurance to cover expenses that would not be covered under the public system. Private health insurance both supplements public insurance and partially duplicates public insurance.

The Australian Federal Government recently introduced three reforms to private health insurance with the stated aim of increasing the take-up of private health insurance. These reforms are the introduction of a thirty-percent subsidy (rebate) on private health insurance premiums, the introduction of a form of life-time insurance coverage and an additional tax penalty on high-income earners who do not have private insurance coverage.

In this paper, we formally analyse the effectiveness and welfare consequences of the health insurance system used in Australia, and consider the affect of the recently introduced rebate for private insurance. We also consider how the existing system could be modified to provide improved welfare outcomes.

Our focus on the insurance properties of the health system is unusual in the Australian debate. The Australian health debate has been driven by concern over government cost containment and the linking of public insurance with the public provision of medical services and private insurance with the private provision of medical care. This linking is a feature of the Australian system but has little if anything to do with insurance. ${ }^{1}$ In contrast, we focus on the ability of the Australian health insurance system to protect individuals from the risk of adverse health events.

Our conclusions are simple. When we consider the welfare of individuals who only differ by their health risk (or equivalently the life-cycle of an average individual) the

\footnotetext{
${ }^{1}$ For example, there is no reason why a system of pure public insurance could not involve service provision through both public and private providers. The ownership of the institutions providing medical services and the nature of health insurance are analytically separate features of a system of health provision.
} 
Australian-style mixed public-private health insurance system creates poor incentives and provides undesirable insurance features. In particular, while protecting against some health risk, the insurance system also increases the underlying risk associated with adverse health events. This arises because under the Australian health insurance system, the most-at-risk individuals provide an implicit subsidy through the tax system to those individuals who have the least risk of an adverse health event. In other words, the underlying health insurance system that currently exists in Australia involves a form of anti-insurance that lowers the overall welfare of the Australian population.

The adverse properties of the existing Australian health insurance system are partially offset by the recently introduced rebate on the private health insurance premiums. $^{2}$ In this sense, the rebate tends to improve welfare. At the same time, however, the rebate distorts the price of private health insurance and may lead to excessive insurance coverage and over-consumption of health services by the most-at-risk groups in society. We suggest that a preferred approach would be a lump-sum rebate on private health insurance premiums. This would provide the insurance benefits of the existing rebate without introducing the undesirable distortion to the marginal price of private health insurance.

This said, we believe that our analysis highlights an important flaw in the design of the Australian health insurance system. It might be desirable to move from the current mixed system to a system where private health insurance would supplement or top-up public insurance rather than duplicating public insurance.

This paper proceeds as follows. Section 2 provides some background to the Australian health insurance system. Section 3 presents the formal model of the Australian health insurance system and the potential equilibrium outcomes. The welfare properties of these outcomes are analysed in section 4 . In particular, section 4 discusses why the Australian-style system creates unnecessary risk or anti-insurance. The recently introduced rebate on private health insurance is also analyzed in section 4 . Section 5 discusses some of the limitations of our model and concludes.

\footnotetext{
${ }^{2}$ At present, 30 percent of private health insurance expenditures are paid for by the Australian government.
} 


\section{Background}

Before presenting the formal model, it is useful to summarize the key features of health insurance in Australia. Jost (2001) notes that various different schemes of public health insurance exist around the world. Some of these (e.g. Germany) allow individuals to opt out. In contrast, public health insurance is mandatory in Australia, in the sense that all citizens are covered and are eligible to receive the benefits associated with this insurance system.

The Australian public health insurance system is largely funded through general taxation revenue. A Medicare Levy is paid by all income tax payers and a Medicare Levy Surcharge is paid by high-income individuals and households, but the cost of operating the public health insurance system far exceeds the total revenue raised by these two taxes. ${ }^{3}$ The vast bulk of funding for the public health insurance system comes from general taxation revenue (both income taxation and other taxation).

Private health insurance in Australia can be purchased through a variety of profit and not-for-profit private institutions as well as through a government-owned health insurance company, Medibank Private. The premiums charged by these institutions for private health insurance are monitored and vetted by the federal government. Purchasing private health insurance provides an individual with a variety of benefits in addition to the public insurance system, although these benefits depend on the exact nature of the insurance policy purchased by the individual.

The benefits fall into two classes. First private insurance may supplement public health insurance. For example, private insurance can cover optical and dental services not covered by the public insurance. ${ }^{4}$ Private health insurance can also cover a higher quality of medical service than public insurance, such as having a single-bed room, greater physician choice and reduced waiting times. ${ }^{5}$ Supplemental insurance is examined by

\footnotetext{
${ }^{3}$ The Medicare Levy Surcharge is waived if the relevant individual or household has private hospital health insurance.

${ }^{4}$ Private insurance in Canada also covers these types of services; see Jost (2001).

${ }^{5}$ For example, private insurance may cover 'elective' surgery reducing patient waiting times. These waiting times can be significant. For example the median public hospital (covered by public insurance) waiting time was 11 days for cardio-thoracic surgery, 52 days for ophthalmologic surgery, 16 days for coronary artery bypass graft and 114 days for total knee replacement. Private health insurance often covers a patient if they choose to by-pass these queues and reduce the waiting time by using a private hospital. This private-
} 
Finkelstein (2002). Second, private health insurance benefits duplicate public insurance benefits. For example, if a patient decides to use private health insurance for a procedure (as a private patient in a private hospital) then the private insurance company and the patient pay for the hospital accommodation services even though the government would cover those expenses under the public insurance system (in a public hospital). In this situation, the individual who is privately insured takes out insurance that makes the public insurance either fully or partially redundant. ${ }^{6}$

Thus, private health insurance in Australia has two broad features - it provides a greater degree of health insurance than the public insurance but it also duplicates the public insurance. At the same time, until the recent tax rebate was introduced by the Federal government, an individual who took out private health insurance cover received no reduction in tax funding for the public system. While the privately insured individual would reduce the total cost associated with the pubic system (as they would no longer claim the public benefit if ill) they did not receive any ex ante reduction in taxes.

Because the payments for publicly-insured health care come through the tax system rather than through explicit premiums, any change to the public health insurance system has fiscal implications for government. As we noted above, this has resulted in debate about government costs driving the health policy debate regarding private insurance in Australia and health insurance policy is often critiqued from the perspective of government costs (e.g. Hurley et.al., 2002; Duckett and Jackson, 2000). ${ }^{7}$ In contrast, we consider the insurance properties of the Australian system.

Australian debate about health insurance has also focused on income distribution. Some analysts appear to view the health insurance system as a scheme for redistributing

\footnotetext{
hospital alternative is available to all individuals but in the absence of private insurance the patient has to bear much of the costs of the procedure themselves.

${ }^{6}$ Private patients are also eligible to receive services in public hospitals but the payment for these services can depend on whether the patient 'declares' that they are a public patient or have private insurance. The incentive for declaration by a patient when accessing overlapping services is an issue worthy of further analysis, but is beyond the scope of this paper.

${ }^{7}$ It should be noted that this focus is also adopted by the federal government. In this sense, commentators analysing the insurance system purely from a government-cost perspective can legitimately argue that they are merely adopting the government's stated objective. For example, Vaithianathan (2002) formally models the introduction of the private insurance rebate and shows that its effect on government cost, at best, is ambiguous.
} 
income through the tax system. ${ }^{8}$ While income redistribution is a laudable objective, it is far from clear that this redistribution should occur through the health insurance system. Standard economics suggests that income redistribution should occur through clear, welldefined taxation and redistribution systems. Hiding income redistribution through a public health insurance system is likely to be inefficient. For our analysis we separate out the aim of socially desirable income redistribution through the taxation and social security systems and the design of a socially desirable health insurance system. ${ }^{9}$ To do otherwise is to confuse two separate welfare issues.

Finally, private health insurers in Australia are required to implement 'community rating,' so that insurers cannot offer different packages to different individuals based on their risk type (relating say to age, medical history or other observables). Insurers, however, can offer multiple insurance packages and allow individuals to self select a preferred policy. Vaithianathan (2000) argues that insurers may have a greater incentive to experiment with package design when community rating policies are in force. ${ }^{10}$

Under community rating, we would expect relatively high risk individuals to be more likely to purchase private insurance. This is consistent with both our model and with the Australian evidence (Barrett and Conlon, 2002). ${ }^{11}$

\footnotetext{
${ }^{8}$ For example, Smith (2001) argues that the recent government reforms are undesirable as they provide greater benefits to richer households and that by reducing tax revenue available for other health measures, the reforms undermine the public health system. This argument unnecessarily combines the welfare implications of taxation and the design of health insurance incentives. It might be socially desirable to have higher taxes on the rich, but this is a different issue to providing social incentives to take out private health insurance.

9 Thus, we share the focus of Jack (1998, p.154) who treats as separate issues of income distribution: "[N]otwithstanding some externality and public goods attributes of certain medical interventions, given the essentially private-good nature of health care consumption and health insurance, it is likely to be more efficient for the government to address questions of income distribution directly through the tax system...."

${ }^{10}$ She points to policies that exclude hip replacement as ones that appeal to younger individuals.

${ }^{11}$ Note that older individuals are more likely to have a high health risk. Thus the use of hospitals (both public and private) tends to be skewed towards the older members of the population. Australians over 65 years of age made up only approximately $12.3 \%$ of the population in $2000-01$ but accounted for $33.1 \%$ of total hospital separations and $48.0 \%$ of patient days (Australian Institute of Health and Welfare, 2002). In this sense, by including both high and low risk individuals, our model can be thought to apply to either the Australian population at one point in time or to an individual facing changing health risk over their lifetime.
} 


\section{A Model of Health Insurance}

\subsection{Modeling welfare and health insurance}

There is a population of individuals each of whose utility depends on health status and disposable income. ${ }^{12}$ First, consider health status. There are two relevant dates in time. In the first period, denoted $t=1$, (the ex ante period), individuals are uncertain about their future health status. Each individual faces two alternative states of nature and these states of nature are realized in the second period ( $t=2$, the ex post period). The alternative states of nature are referred to as 'well' or 'ill.' If an individual is 'ill' in the second period then they require health expenditure $H$. This expenditure is not required if the individual is 'well' at $t=2$. Hence, if the individual is ill then this is equivalent to a reduction in ex post disposable income by $H$.

In the second period, individuals will differ by their realized health status. But ex ante, before health status is realized, individuals only differ by their probability of being either ill or healthy in the second period. There are two types of individuals, 'high risk' types (denoted by $h$ ) who ex ante have a relatively high probability of being ill in the future and 'low risk' types (denoted by $l$ ) who ex ante are less likely to require health expenditure in the second period. We denote the ex ante probability that an individual of type $i \in\{l, h\}$ will be ill in the future by $q_{i}$ where $q_{h}>q_{l}$. We denote the proportion of high-risk types in the population by $p$. In other words, for a randomly chosen member of the population, the probability that the individual is an $h$-type is given by $p$ while the probability that they are an $l$-type is given by $(1-p)$. Each individual knows their type in period 1 , but this is private information to the individual.

Turning to income, all individuals have an identical base income in period 2 of $y$. But if a person is ill in period 2, their disposable income in that period is $y-H$. In the absence of any public or private insurance, an individual's realized period 2 utility is given by $u(y)$ when healthy and by $u(y-H)$ when ill. Ex ante expected income for a

\footnotetext{
${ }^{12}$ The model presented here is a variant of the classic insurance model pioneered by Rothschild and Stiglitz (1976) and Wilson (1977). Finkelstein (2002) uses this framework to consider insurance with multiple contracts (either public or private). For a recent example of this approach applied to the Australian health care system, see Jack (1998).
} 
type $i$ consumer is thus $U_{i}=\left(1-q_{i}\right) u(y)+q_{i} u(y-H)$. We make the usual assumptions on $u$ so that $u^{\prime}>0$ and $u^{\prime \prime}<0$. Thus, we assume that individuals are risk averse and, as such, will value actuarially fair insurance.

An individual has access to either private and/or public health insurance in period 1. Insurance will involve transferring income from the 'healthy' state to the 'ill' state. Private insurance will involve a premium, $P$, and an indemnity, $t$. Both the premium and the indemnity are set by the insurance company in period 1. An individual can then purchase the insurance in period 1, before they learn their health status. An individual who purchases private insurance will have an income of $y-P$ in period 2 when they are healthy and an income of $y-P-H+t$ when they are ill.

The private insurance market is competitive and there are an arbitrarily large number of potential providers of private health insurance. Each private insurance provider seeks to maximize profits but equilibrium profits are constrained by competition. Thus, in equilibrium, if a fraction $\pi_{i}$ of all type- $i$ individuals buy a particular private insurance product then the insurer's average economic profits per member of the population are given by $\left(\pi_{h} p+\pi_{l}(1-p)\right) P-\left(\pi_{h} p q_{h}+\pi_{l}(1-p) q_{l}\right) t$. By competition, these profits equal zero.

It is well known that a pure strategy Nash equilibrium may not exist in the oneshot simultaneous move game between insurance companies (Rothschild and Stiglitz, 1976). As Wilson (1977) showed, this existence problem may be overcome by using an alternative equilibrium concept. As our focus here is on the welfare consequences of public insurance for consumers rather than on the explicit operations of the private insurance market, we assume that, in the absence of public insurance, there is a well defined perfectly-competitive Nash equilibrium in the private insurance market. As Rothschild and Stiglitz note, this will be a separating equilibrium, where the high-risk types are fully insured but the low risk types only receive partial insurance. The contract accepted in equilibrium by the low-risk individuals is the best actuarially fair contract that can be offered without being preferred by the high-risk types to full insurance. The 
inability of low-risk individuals to receive full insurance reflects the adverse selection problem in this model. ${ }^{13}$

Formally, we assume that there is a minimum health $\cos t \underline{H}$ such that, for all $y, H$ such that $H \in(\underline{H}, y)$ there is a well defined separating Nash equilibrium in the private insurance market. Essentially, this assumption requires that there are not 'too few' $h$ types in the economy. ${ }^{14}$

The separating private insurance equilibrium is shown on Figure 1. The $h$-types receive full insurance that is actuarially fair given their probability of illness. The $l$-types also receive actuarially fair insurance given their risk characteristics, but they are not fully insured. The premium paid by the high risk individuals $\left(P_{h}\right)$ is higher than the premium paid by the low risk individuals, but the payment if they are ill $\left(t_{h}\right)$ is also higher.

Public health insurance can also be provided. We consider a fully-funded public system so that total tax revenues equal expected payouts. The tax revenue paid by each member of the population and the members of society who receive a payout will depend on the exact public health policy adopted by the government. The government sets both taxes and the future payouts in period 1. As an individual's type is private information, the government cannot make tax payments contingent on the likelihood of future illness. However, tax payments can be contingent on other factors that are observable in period 1, such as whether or not an individual has purchased private insurance.

Finally, we require a welfare standard for comparing alternative health insurance systems. There is clearly no unique welfare measure. However, given the structure of our model, a sensible approach is to consider the expected welfare of a representative individual, $W=p U_{h}+(1-p) U_{l}$. In other words, for any individual in society, we consider their expected period 2 utility before they learn their type. Thus, we could

${ }^{13}$ An alternative would be to use the Wilson (1977) approach where either a pooling or separating equilibrium always exists under pure private insurance. The Wilson approach however relies on 'one round' of induction. In other words, it considers deviations where some other players can adjust their contracts after a deviation occurs and requires that the deviation remains profitable after these adjustments. This approach is somewhat arbitrary. Further, as we have an additional player (the government) in our framework, it seems more reasonable simply to maintain the standard Nash assumption that the equilibrium must be immune to unilateral deviation by a private insurance firm. 
consider an initial period 0 , where individuals have not yet learnt their type. In this initial period, every individual is identical and has an identical expected utility. This expected utility provides a reasonable measure of social welfare. ${ }^{15}$

\subsection{The outcome with only comprehensive public insurance}

Under comprehensive public insurance, all individuals pay the same tax, $T$, and if sick all individuals receive the same benefit, $b$. The health system must be fully funded so that $T-\left(p q_{h}+(1-p) q_{l}\right) b=0$. There are a large number of potential public insurance schemes, and these are illustrated in Figure 2 by the 'balanced-budget' line under complete pooling. Also illustrated is the preferred level of public insurance that would be chosen by the low-risk types. In contrast, the high-risk individuals would prefer a higher level of public health insurance. In fact, given that they are facing better-than-actuariallyfair odds on public health insurance (due to the pooling with $l$-types) the $h$-types would seek more than full insurance.

We can consider the level of public insurance that will maximize the expected welfare of a representative agent, $W$. The optimal level of public insurance will set $T$ and $b$ to maximize:

$p\left[\left(1-q_{h}\right) u(y-T)+q_{h} u(y-T-H+b)\right]+(1-p)\left[\left(1-q_{l}\right) u(y-T)+q_{l} u(y-T-H+b)\right]$

subject to $T-\left(p q_{h}+(1-p) q_{l}\right) b=0$. From the first order conditions of this problem, the optimal $T$ and $b$ involve setting the marginal utility of income the same whether well or ill. In other word, optimal public insurance involves full insurance. ${ }^{16}$

Optimal public insurance involves community rated full insurance. But this situation does not exist in Australia. While public health insurance has community rating, it does not provide full insurance in the sense that it does not cover all medical conditions and it limits the quality of service that is covered for so called elective health procedures.

\footnotetext{
${ }^{14}$ This assumption is critical to showing the existence of equilibria for the mixed public-private system. Without this assumption, the non-existence problems raised by Rothschild and Stiglitz can reappear in our model.

${ }^{15}$ In our model, this is equivalent to a utilitarian welfare function for a large population.

${ }^{16}$ This result is equivalent to saying that community rated full insurance is optimal when an individual does not know their own type. This result is well known in the health insurance literature. See Cutler and Zeckhauser (2000).
} 


\subsection{Outcomes in a mixed public-private system}

We now consider the possible outcomes of a mixed public/private insurance system where an individual can take out private insurance in period 1 but only by forgoing the benefits of public insurance and without receiving a tax rebate. ${ }^{17}$ Then in the next section we consider the welfare consequences of these outcomes.

\section{No take-up of public insurance}

If there is only a very low level of public insurance, the only equilibrium will involve private insurance. In this situation, the public system is meaningless in equilibrium: no-one uses the public system and the government collects no taxes to fund this system in equilibrium. The outcome will be identical to the separating private equilibrium in figure 1. This case is illustrated in Figure 3.

\section{Separating public-private insurance}

At higher levels of public insurance, there may exist an equilibrium where it is worthwhile for the low-risk types to "save their premiums" and use public insurance rather than private insurance, even though high-risk individuals still buy private health insurance. In equilibrium, there will be separation between different types of individuals. The $h$-types take private insurance and the $l$-types use public insurance. With separation, the $h$-types would be fully insured but they would pay both the tax contribution to the public insurance and the private insurance premium.

Formally, a separating public-private equilibrium will involve per person tax $T$, a public insurance benefit $b$, a private premium $P$ and a private indemnity $t$ such that:

$$
\begin{gathered}
P-q_{h} t=0 \\
y-T-H-P+t=y-T-P \\
u(y-T-P) \geq q_{h} u(y-T-H+b)+\left(1-q_{h}\right) u(y-T)
\end{gathered}
$$

\footnotetext{
${ }^{17}$ As already noted, it is possible for an individual with private health insurance to fail to declare this insurance and to be treated under public insurance. The incentives to 'non-declare' relate to specific details of the Australian system and are beyond the scope of the analysis here. Rather, we assume that if an individual buys private health insurance that is more comprehensive than public health insurance then they will use that private insurance if necessary.
} 


$$
u(y-T-P) \leq q_{l} u(y-T-H+b)+\left(1-q_{l}\right) u(y-T)
$$

and

$$
T-(1-p) q_{l} b=0
$$

Equation (1) requires that the $h$-type individuals face actuarially fair insurance while equation (2) involves the $h$-type purchasing full insurance. Together, these equations imply that $t=H$. Equations (3) and (4) are the incentive compatibility constraints for the $h$-type and $l$-type respectively. The former requires that the $h$-type prefer full private insurance to the public insurance. The latter requires that the l-type prefer the public insurance rather than the private insurance offered to the $h$-type individuals. We also require that the tax funding of the public system is balanced and this is captured by equation (5).

Private and public contracts that satisfy (1) to (5) will only constitute a separating equilibrium if there is no unilateral deviation by a private company that would lead to positive profits. Two forms of deviation are possible - where only low-risk individuals are attracted to the 'deviant' contract and where all individuals prefer the deviant contract. Consider the first type of deviation and let $(\tilde{P}, \tilde{t})$ be the insurance contract such that $u(y-T-P)=q_{h} u(y-T-\tilde{P}-H+\tilde{t})+\left(1-q_{h}\right) u(y-T-\tilde{P})$ and $\tilde{P}-q_{l} \tilde{t}=0$. This is the best contract for low-risk types, given tax payments, that just makes high-risk types indifferent to purchase. Thus, $(\tilde{P}, \tilde{t})$ represents the 'best' non-loss-making deviation from the perspective of the low-risk types. If this deviation cannot attract the low-risk types, then no profitable deviation is possible. Thus, we require that

$$
q_{l} u(y-T-H+b)+\left(1-q_{l}\right) u(y-T) \geq q_{l} u(y-T-\tilde{P}-H+\tilde{t})+\left(1-q_{l}\right) u(y-T-\tilde{P})
$$

Now, consider a pooling deviation. There will be no deviation contract that will attract both $l$-types and $h$-types if there does not exist a $(\tilde{P}, \tilde{t})$ such that $\tilde{P}-\left(p q_{h}+(1-p) q_{l}\right) \tilde{t}=0$ and equation (6) is violated.

Proposition 1 shows the existence of a separating public-private equilibrium.

Proposition 1: Let $\hat{y}=y-(1-p) q_{l} b$. For any level of illness $H \in(\underline{H}, \hat{y})$, there exits a public insurance scheme $b$ such that in equilibrium only the low-risk types use public insurance while the high-risk types purchase complete private insurance. 
PROOF: Note that $\hat{y}$ is equal to endowment income less the equilibrium per person tax from (5). By substitution, equation (3) becomes $u\left(\hat{y}-q_{h} H\right) \geq q_{h} u(\hat{y}-H+b)+\left(1-q_{h}\right) u(\hat{y})$. Note that for any $H>0$, if $b$ is sufficiently low (but positive) then $u\left(\hat{y}-q_{h} H\right)-\left[q_{h} u(\hat{y}-H+b)+\left(1-q_{h}\right) u(\hat{y})\right] \quad$ is arbitrarily close to $u\left(y-q_{h} H\right)-\left[q_{h} u(y-H)+\left(1-q_{h}\right) u(y)\right]$ and this is strictly positive by risk aversion. Also, for any $H$, if $H=b$ then $u\left(\hat{y}-q_{h} H\right)-\left[q_{h} u(\hat{y}-H+b)+\left(1-q_{h}\right) u(\hat{y})\right]<0 \quad$ by first order stochastic dominance. Further, both $u\left(\hat{y}-q_{h} H\right)$ and $q_{h} u(\hat{y}-H+b)+\left(1-q_{h}\right) u(\hat{y})$ are continuous in both $H$ and $b$. Thus by the intermediate value theorem, for any $H$ there exists at least one value of $b$ such that $u\left(\hat{y}-q_{h} H\right)-\left[q_{h} u(\hat{y}-H+b)+\left(1-q_{h}\right) u(\hat{y})\right]=0$.

Consider such a value of $b$ and the pair $(H, b)$. By construction, this pair with the associated tax and private insurance satisfies equations(1), (2), (3) and (5). As $q_{l}<q_{h}$ it immediately follows that equation (4) is satisfied.

It remains to show that no profitable deviation exists for $(H, b)$. Note that the relevant contract to check a 'separating' deviation is the same as the separating equilibrium contract for an $l$-type when endowment income is $\hat{y}$. By assumption, such a private separating equilibrium exists for $H>\underline{H}$ so that this contract must be preferred by the l-type individuals to any profitable pooling deviation contract. Thus, if a profitable 'separating' deviation does not exist, a profitable 'pooling' deviation cannot exist. That no profitable separating deviation exists, however, follows trivially. By construction full private insurance, the public insurance and the deviation contract $(\tilde{P}, \tilde{t})$ all make a $h$-type indifferent.

But as $q_{l}<q_{h}$ and the deviation contract involves less 'income when well' than public insurance due to the payment of a private premium as well as the tax, the $l$ type individuals strictly prefer public insurance to the 'separating' deviation contract. Thus there is no profitable deviation and for any $H \in(\underline{H}, \hat{y})$ we have found a $b$ that satisfies all relevant conditions for a separating public-private equilibrium. $Q E D$.

A separating public-private equilibrium is illustrated in Figure $4 .^{18}$

\footnotetext{
${ }^{18}$ Note that unlike supplemental private insurance, the public insurance contract is not the 'endowment point' for $h$-types. This is because these types opt out of the public insurance benefits when purchasing private health insurance.
} 


\section{Partial-pooling public-private insurance}

In addition to fully separating equilibria, there are also equilibria where some high-risk individuals utilise public insurance while others use private insurance. Suppose that a fraction $\phi$ of high-risk individuals opt out of public insurance and purchase private insurance. These individuals will be able to fully insure through private insurance but will also be indifferent between paying for such full insurance privately and receiving a lower level of benefits under the public insurance scheme. Equilibrium will be characterised by the following conditions:

$$
\begin{gathered}
P-q_{h} t=0 \\
y-T-H-P+t=y-T-P \\
u(y-T-P)=q_{h} u(y-T-H+b)+\left(1-q_{h}\right) u(y-T) \\
u(y-T-P) \leq q_{l} u(y-T-H+b)+\left(1-q_{l}\right) u(y-T) \\
T-(1-p) q_{l} b-(1-\phi) p q_{h} b=0
\end{gathered}
$$

Equations (7), (8) and (10) are the same as equations (1), (2) and (4). Equation (9) requires that the high-risk individuals are indifferent between public and private insurance, while equation (11) means that the public insurance scheme is fully funded from tax revenues given the risk profile of public insurance claimants. Finally there is a deviation requirement given the level of taxes analogous to the requirement for separating equilibria.

Proposition 2: Let $\hat{y}=y-(1-p) q_{l} b-(1-\phi) p q_{h} b$. For any level of illness $H \in(\underline{H}, \hat{y})$ and any fraction $\phi \in(0,1)$, there exists a public insurance scheme $b$ such that in equilibrium all the low-risk individuals and a fraction $(1-\phi)$ of high-risk individual use public insurance while the remaining high-risk types purchase private insurance.

PROOF: The proof is similar to the proof of Proposition 1. $\hat{y}$ is the endowment income less equilibrium per person tax. By substitution, equation (9) becomes

$$
u\left(\hat{y}-q_{h} H\right)-\left[q_{h} u(\hat{y}-H+b)+\left(1-q_{h}\right) u(\hat{y})\right]=0
$$

Note that for any $H \in(\underline{H}, \hat{y})$ and $\phi \in(0,1)$, if $b$ is sufficiently low (but positive) then the left hand side of (12) is positive by risk aversion and if $b=H$ then the left-hand-side of (12) is negative by first order stochastic dominance. Thus by 
continuity for any $H$ and $\phi$ there exists a value of $b$ such that equations (7), (8), (9), and (11) are simultaneously satisfied. Equation (10) holds as $q_{l}<q_{h}$. Deviations are not profitable by the same argument presented in the proof of proposition 1 . Thus for any $H \in(\underline{H}, \hat{y})$ and $\phi \in(0,1)$, there exists a $b$ such that $(H, \phi, b)$ form a partial pooling equilibrium.

QED.

\section{Public Pooling equilibria}

If public insurance is sufficiently generous then the existence of tax-funded public insurance can eliminate private insurance. Despite public insurance offering less than complete cover, the high-risk individuals prefer to forgo private insurance and use the public scheme. They do this because, at the margin, use of the public insurance scheme is free. All individuals pay for this scheme through their taxes and do not receive a rebate if they opt out of the public scheme. In contrast, private insurance has a direct avoidable cost for individuals.

A public pooling equilibrium with no private insurance will exist whenever (7), (8), (10) and (11) hold for $\phi=0$ with equation (9) replaced by:

$$
u(y-T-P)<q_{h} u(y-T-H+b)+\left(1-q_{h}\right) u(y-T)
$$

(13) requires that high-risk individuals all prefer to use public insurance rather than to purchase actuarially fair private insurance. Given this, no high-risk individuals opt out of public insurance and the cost of the public insurance is borne by individuals through their taxes.

\subsection{An example with constant risk aversion}

We can illustrate the separating and partial-pooling outcomes by a simple example. Suppose that individuals have a utility function, $u(Y)=-e^{-a Y}$. This utility function has a constant Arrow-Pratt index of risk aversion given by $a .{ }^{19}$ In this situation (12) can be written as $-e^{-a\left(\hat{y}-q_{h} H\right)}+\left[q_{h} e^{-a(\hat{y}-H+b)}+\left(1-q_{h}\right) e^{-a(\hat{y})}\right]=0 \quad$ where $\hat{y}=y-(1-p) q_{l} b-(1-\phi) p q_{h} b$. Proposition 3 shows that if individuals have constant risk aversion then the value of $b$ associated with a partial pooling equilibrium is unique. 
Proposition 3: Suppose individuals have constant risk aversion utility. Then for any level of illness $H \in(\underline{H}, \hat{y})$ and any fraction $\phi \in(0,1)$, there exists a unique public insurance scheme $b^{*}$ such that in equilibrium all the low-risk individuals and a fraction $(1-\phi)$ of high-risk individual use public insurance while the remaining high-risk types purchase private insurance. Further $b^{*}$ is invariant in $\phi$.

PROOF: By Proposition 2, we know that for any $H \in(\underline{H}, \hat{y})$ and $\phi$, there exists a value $b$ that leads to a partial pooling equilibrium. To show that this is unique for constant risk aversion utility, note than in this situation, the derivative of the lefthand-side of (12) with respect to $b$ is given by $-a \frac{\partial \hat{y}}{\partial b}\left[-e^{-a\left(\hat{y}-q_{h} H\right)}+\left[q_{h} e^{-a(\hat{y}-H+b)}+\left(1-q_{h}\right) e^{-a(\hat{y})}\right]\right]-a q_{h} e^{-a(\hat{y}-H+b)}$. But by

the first term equals zero so that the derivative of the left-hand-side of (12) with respect to $b$ is $-a q_{h} e^{-a(\hat{y}-H+b)}<0$. Thus, as the left-hand-side of (12) is monotonic in $b$, for any $H$ and $\phi$ there is a unique $b$ such that equation (12) is satisfied. Denote this value by $b^{*}$

To show that $b^{*}$ is invariant in $\phi$, consider any $H \in(\underline{H}, \hat{y})$ and $\phi \in(0,1)$ and the associated $b^{*}$ that solves equation (12). The derivative of the left-hand-side of (12) with respect to $\phi \quad$ is given by $-a \frac{\partial \hat{y}}{\partial \phi}\left[-e^{-a\left(\hat{y}-q_{h} H\right)}+\left[q_{h} e^{-a(\hat{y}-H+b)}+\left(1-q_{h}\right) e^{-a(\hat{y})}\right]\right]$. But by (12), this equals zero. Thus, if $b^{*}$ solves (12) for any particular $H$ and $\phi$, then it solves (12) for that value of $H$ and any value of $\phi$. Thus, $b^{*}$ is invariant in $\phi$. QED.

While Proposition 3 only applies to constant risk aversion utility functions, it is a strong result. It says that given the values of the exogenous parameters, $y, H, p, q_{l}$, and $q_{h}$, there is a unique level of public health insurance that will lead to a partial-pooling publicprivate insurance outcome. Further, there is a continuum of equilibria at this level of public health insurance. At one extreme of these equilibria there exists a separating mixed public-private outcome. At the other extreme there is only public insurance.

Table 1 calculates the value of $b^{*}$ for a situation where income is equal to $\$ 40,000$; the income-equivalent cost of illness is $\$ 10,000$, the probability that any individual is high-risk is one-quarter, the probability of a high risk individual being ill is one-tenth while the probability of a low risk individual becoming ill is (1/100). If public health benefits exceed $b^{*}$ then there is only public insurance with no private insurance. If

\footnotetext{
${ }^{19}$ See Hirshleifer and Riley (1992) for a discussion on measures of risk aversion.
} 
public health benefits fall below $b^{*}$ then there is either separating public-private insurance or just private insurance is the outcome.

Table 1

(Parameters: $y=\$ 40,000, H=\$ 10,000, p=0.25, q_{1}=0.01$ and $q_{\mathrm{h}}=0.1$ )

\begin{tabular}{|c|c|}
\hline Risk aversion $(a)$ & Critical level of public insurance $\left(b^{*}\right)$ \\
\hline 0.25 & $\$ 4,618$ \\
\hline 0.5 & $\$ 5,974$ \\
\hline 1 & $\$ 7,010$ \\
\hline 2 & $\$ 7,914$ \\
\hline 4 & $\$ 8,429$ \\
\hline
\end{tabular}

Table 1 considers a variety of degrees of risk aversion for individuals, from relatively low to very high. As expected, the more risk averse are individuals, the higher is $b^{*}$. This reflects that, as individuals are more risk averse, greater public insurance is required to lure high-risk individuals away from the more comprehensive insurance available from private insurers. Even though the high-risk individuals are paying for the public insurance through their taxes, they are willing to opt out and buy private insurance if the public insurance benefits are too low (less than $b^{*}$ ).

\section{Outcomes of the Australian Health Insurance System}

We have identified four possible outcomes of the Australian mixed public-private insurance system. The outcomes with only private insurance or only public insurance are well understood. However, both the separating public-private outcome and the partial pooling outcome raise important welfare issues. Further, these outcomes most accord with the 'separating' behavior of the Australian population. In this section we consider the welfare consequences of these outcomes and show that, in general, both the separating and partial pooling outcomes have undesirable welfare consequences.

\subsection{Anti-insurance with separating public-private insurance}

There are a number of points to note about the separating equilibrium. First, the high-risk individuals in equilibrium are always worse off than if there were no public health insurance. In other words, they are worse off than the separating private insurance 
equilibrium. ${ }^{20}$ The reason for this is simple. With the public insurance the high-risk types receive inadequate health coverage given their level of risk but, even if they opt out of the public scheme, they are still required to pay their tax contribution to the public scheme. As such, the high-risk individuals are cross subsidizing the low-risk individuals.

Observation 1: Under a separating public-private equilibrium, those in society who are most likely to be ill will 'opt out' of public insurance and purchase private insurance. The public health insurance will only be used by those in society who are healthiest (i.e. least likely to become ill). The high-risk individuals are made worse off by the public insurance because they are required to cross-subsidise the public insurance of the lowrisk individuals through the tax system.

We are able to characterise the degree of cross-subsidy in a separating public-private equilibrium. To see this, from (1) to (5), the equilibrium utility of a $h$-type individual is given by $u\left(y-(1-p) q_{l} b-q_{h} H\right)$. Note that this is the same utility that a $h$-type would receive under actuarially fair insurance if they started with a base income of $y-(1-p) q_{l} b$ rather than a base income of $y$.

Similarly, in a separating public-private equilibrium the expected utility of an $l$ type is $\left(1-q_{l}\right) u\left(y+p q_{l} b-q_{l} b\right)+q_{l} u\left(y+p q_{l} b-H-q_{l} b+b\right)$. Notice that this is the same utility that a low-risk type would receive if they had a base income of $y+p q_{l} b$ and then purchased actuarially fair insurance for the benefit payment $b$. Thus a separating publicprivate equilibrium involves a situation where high-risk types are treated as if they lose $(1-p) q_{l} b$ dollars in income and then are able to buy full insurance at a fair price while the low-risk types receive an income benefit of $p q_{l} b$ and then purchase insurance $b$ at an actuarially fair price. Notice that such transfers are balanced in that the expected per person transfer to a low-risk type, $(1-p) p q_{l} b$, is exactly equal to the expected per person transfer from a high-risk type.

Observation 2: A separating public-private equilibrium is equivalent to a transfer of $(1-p) q_{l} b$ dollars from individuals with a high health risk and a transfer of $p q_{l} b$ to individuals with a low health risk together with the purchase of actuarially fair insurance.

\footnotetext{
${ }^{20}$ Note that if we followed Wilson (1977) and allowed for pooling equilibria, the high-risk types would still be worse off in a separating public-private equilibrium than in a private pooling equilibrium.
} 
To understand the nature of this transfer, note that $(1-p) q_{l} b$ is the per-person cost of the tax required to fund the public health insurance system. The high-risk individuals gain no benefit from this tax. So their contribution is simply given by the tax funding. But the low-risk individuals use the public insurance. This provides them with a benefit equivalent to $q_{l} b$, the actuarially fair premium associated with the public insurance system. Thus, the net benefit to the low-risk individuals is this insurance benefit less the tax cost, which equals $p q_{l} b$.

These transfers from high-risk to low-risk individuals create clear equity concerns. They involve transfers from those who are ex ante least well off in terms of expected utility and transfers to those who are ex ante better off.

The transfers, however, are not just inequitable. Given the level of insurance coverage, the transfers also lower the measure of social welfare $W$. To see this, consider an individual before they know their type. The individual faces four states of nature depending on their risk category and health status. If the individual is able to buy complete and actuarially fair insurance when high-risk and partial but actuarially fair insurance with an indemnity $b<H$ when low risk, then their income in each state is given by:

$$
\begin{aligned}
& \text { Income }=y-q_{h} H \text { with probability } p q_{h} \quad \text { (high-risk and ill) } \\
& \text { Income }=y-q_{h} H \text { with probability } p\left(1-q_{h}\right) \quad \text { (high-risk and well) } \\
& \text { Income }=y+\left(1-q_{l}\right) b-H \text { with probability }(1-p) q_{l} \quad \text { (low-risk and ill) } \\
& \text { Income }=y-q_{l} b \text { with probability }(1-p)\left(1-q_{l}\right) \quad \text { (low-risk and well) }
\end{aligned}
$$

Consistent with the incentive compatibility constraints for a separating equilibrium, suppose that $y+\left(1-q_{l}\right) b-H<y-q_{h} H<y-q_{l} b$. Note that if this did not hold then there could not be separation as the payoffs for one risk-type of individual would strictly dominate those for the other risk-type. Holding $b$ fixed, apply the transfers associated with a separating public private equilibrium. This alters the state contingent income for the individual to:

$$
\begin{array}{ll}
\text { Income }=y-(1-p) q_{l} b-q_{h} H \text { with probability } p q_{h} & \text { (high-risk and ill) } \\
\text { Income }=y-(1-p) q_{l} b-q_{h} H \text { with probability } p\left(1-q_{h}\right) & \text { (high-risk and well) } \\
\text { Income }=y+p q_{l} b+\left(1-q_{l}\right) b-H \text { with probability }(1-p) q_{l} & \text { (low-risk and ill) } \\
\text { Income }=y+p q_{l} b-q_{l} b \text { with probability }(1-p)\left(1-q_{l}\right) & \text { (low-risk and well) }
\end{array}
$$


But these transfers are a mean preserving spread of income. The transfers do not alter the individual's expected income but involve moving income from states with 'moderate' income to those with 'extreme' income in a way that holds the mean income level fixed. But if individuals are risk averse, then such a mean-preserving spread of income will lead to a lower level of expected utility.

Observation 3: The income transfers associated with a separating public-private equilibrium are strictly welfare reducing in the sense that given the level of public insurance benefit $b$, welfare, $W$, would be strictly greater if the income transfers were eliminated with high-risk individuals still able to purchase full insurance and low-risk individuals able to insure at level $b$ at actuarially fair prices.

\subsection{Anti-insurance and partial-pooling public-private insurance}

As with the separating public-private equilibrium, we can consider the income transfers implicit in a partial-pooling outcome. For the high-risk individuals, both those who use public insurance and those who opt-out and use private insurance have identical utility. This is given by $u\left(y-(1-p) q_{l} b-(1-\phi) p q_{h} b-q_{h} H\right)$. For the low-risk individuals, utility is given by

$$
q_{l} u\left(y-(1-p) q_{l} b-(1-\phi) p q_{h} b-H+b\right)+\left(1-q_{l}\right) u\left(y-(1-p) q_{l} b-(1-\phi) p q_{h} b\right) .
$$

This is equal to

$$
q_{l} u\left(y+p q_{l} b-(1-\phi) p q_{h} b-H+b-q_{l} b\right)+\left(1-q_{l}\right) u\left(y+p q_{l} b-(1-\phi) p q_{h} b-q_{l} b\right) .
$$

Hence the equilibrium welfare for the high-risk individuals is the same as if they were taxed a lump sum equal to $(1-p) q_{l} b+(1-\phi) p q_{h} b$ and then were able to fully insure at an actuarially fair price. The utility of low risk individuals is the same as if they received a lump sum transfer of $p q_{l} b-(1-\phi) p q_{h} b$ followed by actuarially fair insurance of level $b$. This transfer is positive for high values of $\phi$ but is negative as fewer high risk individuals opt out.

If we add up the implicit transfers in equilibrium for a partial pooling equilibrium, then the per-person "revenues collected" are equal to $(\phi p)\left[(1-p) q_{l} b+(1-\phi) p q_{h} b\right]$. Notice that this is the revenue transfer from a high-risk individual who chooses private insurance times the probability that any individual is both high-risk and opts out of public 
insurance. The implicit per-person "revenues paid" equals $(1-\phi p)\left[p q_{l} b-(1-\phi) p q_{h} b\right]$. This is the implicit transfer times the probability that an individual will choose public insurance. Notice that public insurance is now used by all low-risk individuals and a proportion of the high risk individuals. The difference between implicit transfers is given by $(1-\phi) p b\left[q_{h}-q_{l}\right]$ which is strictly positive. In other words, the total implicit revenue collected exceeds the total implicit revenue paid.

The difference between implicit payments is due to the effect of pooling in a partial pooling equilibrium. Note that, in equilibrium, the high-risk types who choose public insurance are no better off than the high-risk types who buy private insurance. The saving to a high-risk individual due to lower premiums and the avoidance of the implicit transfer from individuals who privately insure is exactly offset by the reduction in insurance under the public scheme relative to the full insurance under the private scheme. But the low-risk individuals lose in a partial pooling equilibrium because the public system now involves actuarially unfair insurance from their perspective. The public system provides insurance for both low-risk and some high-risk individuals and, as a result, the tax revenue required is not 'actuarially fair' from the perspective of a low risk individuals. In this situation, the "lost transfer", $(1-\phi) p b\left[q_{h}-q_{l}\right]$, is a measure of the social deadweight loss in equilibrium relative to system where all parties faced fairly priced insurance.

Observation 4. In welfare terms, the outcome in a partial pooling equilibrium is equivalent to a transfer of $(1-p) q_{l} b+(1-\phi) p q_{h} b$ dollars from individuals with a high health risk and a transfer of $p q_{l} b-(1-\phi) p q_{h} b$ to individuals with a low health risk together with the purchase of actuarially fair insurance. However, there is a deadweight loss in a partial pooling equilibrium relative to a system of transfers and actuarially fair insurance, given by $(1-\phi) p b\left[q_{h}-q_{l}\right]$. This deadweight loss arises because the social insurance scheme is not actuarially fair due to the mixing of low-risk and high-risk individuals.

Observation 4 is similar to Observation 2. As we have seen above, the income transfers associated with the Australian health insurance system have the perverse property of transferring income from high-risk individuals to low-risk individuals. In terms of social 
welfare $W$, these transfers create extra underlying risk in society. This lowers expected social welfare. In this sense, the transfers are a type of anti-insurance.

We can investigate this welfare loss of partial pooling further using the constant risk aversion example presented in section 3.4. As we noted, there is a critical level of public insurance benefits, $b^{*}$, such that there is a continuum of partial pooling equilibria. As Proposition 4 shows, welfare differs between these equilibria. The greater the participation in the public insurance system, the lower the level of welfare for all individuals.

Proposition 4: Suppose individuals have constant risk aversion utility and, for any $H>\underline{H}$ consider $b^{*}$ such that there are partial-pooling public-private equilibria. Then the welfare of all individuals is increasing in the value of $\phi$.

PROOF: First, consider the expected utility of the high-risk individuals. This is given by $U_{h}=-e^{-a\left(\hat{y}-q_{h} H\right)}$. Thus, $\frac{\partial U_{h}}{\partial \phi}=a p q_{h} b^{*} e^{-a\left(\hat{y}-q_{h} H\right)}>0$. Noting that $\frac{\partial \hat{y}}{\partial \phi}=p q_{h} b^{*}$, the welfare of the high-risk individuals is increasing in $\phi$. Now consider the utility of the low-risk individuals. This is given by $U_{l}=-q_{l} e^{-a(\hat{y}-H+b)}-\left(1-q_{l}\right) e^{-a(\hat{y})}$. Thus, $\frac{\partial U_{l}}{\partial \phi}=a p q_{h} b^{*}\left[q_{l} e^{-a(\hat{y}-H+b)}+\left(1-q_{l}\right) e^{-a(\hat{y})}\right]>0$. Hence, both the lowrisk and the high-risk individuals are better off if $\phi$ is larger. $Q E D$.

Proposition 4 shows how increased participation in the public insurance scheme can lower the utility of all individuals in society. In other words, as we move from an equilibrium where high-risk individuals mainly opt-out of public insurance, to an equilibrium where more high-risk individuals take advantage of public insurance, the overall welfare of both the high-risk and the low-risk individuals falls. Clearly, this lowers the level of expected social welfare, $W$.

It is important to note that this outcome does not depend on any 'degradation' of the public health system as more people participate in public insurance. In fact, within our model, the public system is always fully funded through the tax system for a given level of health cover. In other words, the public insurance system is completely being maintained in the face of increased usage. Similarly, there is no 'irrationality' on the part of any individuals. All individuals are choosing their most desired mode of insurance 
from their own perspective. The welfare loss comes about because increased utilization of the public insurance system by high-risk individuals distorts the 'price' of public insurance and creates a deadweight loss that is shared by all members of society.

Proposition 4 highlights a critical feature of public insurance under the Australian system. Increased use of public insurance can be Pareto dominated in the sense that it makes all individuals in society worse off. This is a significant result that has been overlooked by the public health debate. Normally, it is thought that increased use of the public insurance system increases its 'viability' by having greater risk pooling. And, of course, complete pooled public health insurance maximises expected social welfare as noted in section 3.2. But in the absence of complete public insurance, increased use of the public insurance system may undermine the welfare of existing users by adding relatively high-risk individuals back into the public pool. Further, these high-risk individuals do not themselves gain by the expansion of the public insurance system. These individuals, who are most likely to be ill, give up insurance coverage when they move into the public pool.

Observation 5. If individuals have constant risk aversion and we compare two partial pooling equilibria, then the equilibrium with a higher participation in the public system (i.e. a lower rate of 'opt out' by high risk individuals) involves a lower level of welfare for all members of society than the alternative equilibrium.

\subsection{The private insurance rebate}

In 1997, the Australian Federal government began introducing rebates for private health insurance. While initially a lump-sum based on income level, today this rebate reduces the effective price of private health insurance by 30 percent for all individuals. In this section, we consider the implications of such an ad valorem subsidy. We also compare this with a lump sum subsidy.

\section{An ad valorem private insurance rebate}

The 30 percent private insurance rebate has two effects. First, it partially reverses the transfers imposed on high-risk individuals under the Australian health insurance system. Second, it distorts the price of private insurance. 
Denote the fractional rebate on private insurance by $s$. For ease of analysis we will focus on a separating public-private equilibrium. This will involve a per person tax $T$, a public insurance benefit $b$, a private premium $P$, a subsidy $s$ and a private indemnity $t$ such that:

$$
\begin{gathered}
P-q_{h} t=0 \\
t=\arg \max \left(q_{h} u(y-T-(1-s) P+t-H)+\left(1-q_{h}\right) u(y-T-(1-s) P)\right) \\
q_{h} u(y-T-(1-s) P+t-H)+\left(1-q_{h}\right) u(y-T-(1-s) P) \\
\geq q_{h} u(y-T-H+b)+\left(1-q_{h}\right) u(y-T) \\
q_{l} u(y-T-(1-s) P+t-H)+\left(1-q_{l}\right) u(y-T-(1-s) P) \\
\leq q_{l} u(y-T-H+b)+\left(1-q_{l}\right) u(y-T)
\end{gathered}
$$

and

$$
T-(1-p) q_{l} b-p s P=0
$$

(14) is the same as (1) and simply reflects actuarially fair private insurance. (15) replaces the 'full insurance' condition that applies in the absence of the subsidy and generalises (2). (16) and (17) are the incentive compatibility conditions for the separating equilibrium, while (18) requires that total tax revenues pay for both the public insurance scheme and the subsidy to private insurance.

To see how the subsidy distorts the price of private insurance, note from (14) that $P=q_{h} t$. Substituting this into (15) and solving for the optimal amount of private insurance gives

$$
\frac{u^{\prime}(y-T-(1-s) P+t-H)}{u^{\prime}(y-T-(1-s) P)}=\frac{1-q_{h}+s q_{h}-s}{1-q_{h}+s q_{h}}
$$

The left-hand-side of this equation is the ratio of the marginal utility of income when ill to the marginal utility of income when well. If $s=0$ then the right-hand-side of this equation equals 1 , so that the high-risk individual has equal marginal utility (and hence equal income) whether ill or well. In other words, when $s=0$, the high-risk individual buys complete private insurance, as per (2). But if there is a subsidy on private health 
insurance then $s>0$ and the right-hand-side of (19) is less than unity. As such, the individual has higher income when ill than when well. In other words, by distorting the price of private insurance to a 'better than actuarially fair' price, the insurance subsidy leads to over insurance by high-risk individuals. This results in a deadweight loss. In practice, we would expect to see individuals who purchase private insurance buying policies that are 'too comprehensive' and that provide benefits that are valued by the purchaser at less than their true economic cost.

Let the degree of over insurance be represented by $\Delta$. Thus the high-risk individuals purchase insurance $t=H+\Delta$ and the per person tax required to fund both the public insurance and the private subsidy is given by $T=(1-p) q_{l} b+p s q_{h}(H+\Delta)$. The equilibrium expected utility of a high-risk individual is given by

$$
\begin{aligned}
& U_{h}=q_{h} u\left(y-(1-p) q_{l} b+s q_{h}(1-p)(H+\Delta)+\left(1-q_{h}\right) \Delta-q_{h} H\right)+ \\
& \left(1-q_{h}\right) u\left(y-(1-p) q_{l} b+s q_{h}(1-p)(H+\Delta)-q_{h} \Delta-q_{h} H\right)
\end{aligned}
$$

while the expected utility of a low-risk individual is

$$
\begin{aligned}
& U_{l}=q_{l} u\left(y+p q_{l} b-p s q_{h}(H+\Delta)-H+b-q_{l} b\right)+ \\
& \left(1-q_{l}\right) u\left(y+p q_{l} b-p s q_{h}(H+\Delta)-q_{l} b\right)
\end{aligned}
$$

The subsidy effectively reverses some of the transfer from high-risk to low-risk individuals under the mixed public-private insurance system. Consider the low-risk individuals. As before, their utility can be broken into a transfer component and an insurance component. Thus, their utility is the same as if they received an income transfer of $p q_{l} b-p s q_{h}(H+\Delta)$ followed by the purchase of a level of insurance $b$ at actuarially fair prices. As before, this transfer includes a subsidy from high-risk individuals to lowrisk individuals through the tax system for the public insurance scheme. But the transfer is reduced by the cost of the private insurance subsidy. This is given by the size of the subsidy $(s)$ times the probability that an individual is both high-risk and ill $\left(p q_{\mathrm{h}}\right)$, times the amount of insurance purchased by high-risk individuals $(H+\Delta)$. Notice that as the size of the subsidy $s$ increases (which will lead to an increase in $\Delta$ ), the size of the transfer to low risk individuals falls. 
The high-risk individuals' utility is slightly more complex. Their income is equivalent to them making a lump-sum transfer of $(1-p) q_{l} b-s q_{h}(1-p)(H+\Delta)$, purchasing complete actuarially fair insurance for $q_{l} H$, and then also taking out an extra gamble with expected payoff of zero. In the state where the high-risk individual is ill, they receive an extra payment of $\left(1-q_{h}\right) \Delta$. This occurs with probability $q_{h}$. But they pay $q_{h} \Delta$ for this in the state where they are well (i.e. with probability $\left(1-q_{h}\right)$ ).

As in the separating equilibrium without an insurance subsidy, the transfers are balanced in the sense that the total payments by high-risk individuals equal the total receipts by low-risk individuals. But the subsidy not only reverses the transfer between the high-risk and low-risk individuals, it also creates a deadweight loss due to over insurance, and this is reflected by the additional risk incurred by the high risk individuals. The high-risk individuals buy a fair gamble. But as they are risk averse, the welfare gain to the high risk individuals from this gamble is negative. The high risk individuals only purchase the gamble because they receive a subsidized price and the loss of utility due to the purchase of the fair gamble is a measure of the deadweight loss created by the subsidy.

Observation 6. In a separating equilibrium the government rebate on private health insurance reduces the transfer from the high-risk individuals to the low-risk individuals. At the same time, the rebate creates a deadweight loss through over insurance that creates a welfare loss for the high-risk individuals.

The reduction in the transfers from high-risk to low-risk individuals raises social welfare $W$. This follows directly from the discussion of separating equilibria. The transfers tend to increase social risk. So anything that reduces these transfers (but maintains balance so that expected income is not affected) will raise welfare. In this sense, the private insurance subsidy is welfare improving.

It should be noted that this improvement in welfare due to the private insurance subsidy is not related to the level of cover provided by public insurance. The public insurance coverage is constant in our model, although the burden of funding that insurance shifts from high-risk to low-risk individuals when the subsidy is introduced. Similarly, the welfare improvement does not involve a change in the absolute numbers using public or private insurance. In fact, in a separating equilibrium, the number of 
individuals using public and private insurance is unchanged after the introduction of the subsidy.

Rather, the welfare improvement is due to a reduction in social risk. The subsidy effectively raises the utility of those who are most likely to be worse off in society. From a social perspective, the cost of being ill is reduced by the subsidy.

This said, as Observation 6 notes, the private insurance subsidy itself introduces a new distortion leading to excessive private insurance. In the next subsection, we consider how the benefits associated with a subsidy can be achieved without incurring this additional deadweight loss.

\section{A lump sum private insurance rebate}

Suppose that rather than subsidizing the price of private health insurance, the government provides a fixed lump sum rebate, $L$, to individuals who purchase private health insurance. The public-private separating equilibrium that arises in these circumstances is given by:

$$
\begin{gathered}
P-q_{h} t=0 \\
y-T+L-H-P+t=y-T+L-P \\
u(y-T+L-P) \geq q_{h} u(y-T-H+b)+\left(1-q_{h}\right) u(y-T) \\
u(y-T+L-P) \leq q_{l} u(y-T-H+b)+\left(1-q_{l}\right) u(y-T) \\
T-(1-p) q_{l} b-p L=0
\end{gathered}
$$

The lump sum rebate does not distort the marginal price of private health insurance. As such, the high-risk individuals who purchase private health insurance will choose full insurance at actuarially fair prices. The rebate must be funded out of tax collections.

Under a lump sum rebate, the utility of the high-risk individuals is given by $U_{h}=u\left(y-(1-p)\left(q_{l} b-L\right)-q_{h} H\right)$. The utility of the low-risk types is given by $U_{l}=q_{l} u\left(y+p\left(q_{l} b-L\right)-H+b-q_{l} b\right)+\left(1-q_{l}\right) u\left(y+p\left(q_{l} b-L\right)-q_{l} b\right)$. Thus with a lump sum rebate the separating public-private equilibrium involves a net transfer of $(1-p)\left(q_{l} b-L\right)$ from each high risk individual with a net transfer of $p\left(q_{l} b-L\right)$ to each 
low-risk individual. If these transfers are positive then they increase social risk. As the transfers are decreasing in $L$, social welfare $W$ is increasing in $L$ for any given level of public insurance $b$. The transfers are completely eliminated if $L=q_{1} b$.

Observation 7. Social welfare is increasing as the rebate $L$ increases. If $L=q_{l} b$ then the lump-sum rebate completely reverses the income transfers implicit in the current Australian health insurance system.

The lump-sum private insurance rebate has all the desirable properties of the ad valorem subsidy but avoids the undesirable price distortion created by that subsidy.

\section{Reforming the Australian Health Insurance System}

The results presented above are based on a simplified model of the Australian mixed public-private health insurance system. In our opinion, however, the model captures the key features of the Australian system and our results are robust to a variety of extensions.

\section{Non-competitive health insurance}

Our model assumed competitive private provision of health insurance. It is beyond the scope of this paper to consider the structure and degree of competition in private insurance in Australia. But even if the private health insurance industry was highly imperfectly competitive, our key anti-insurance results remain valid.

For example, suppose there was a monopoly private insurer and consider a separating outcome. Given the public health scheme, the insurer would offer high risk individuals a complete insurance contract that would just make them prefer private to public insurance. The high-risk individuals would be worse off than with a competitive private insurance market but the transfer from high-risk to low-risk individuals would remain. The high risk individuals would however also be making a profit transfer to the monopoly insurer. In other words, the inequities of the Australian system are worsened under imperfect private insurance and a lack of competition simply makes the system worse, not better. ${ }^{21}$

\footnotetext{
${ }^{21}$ It is useful to note that in the case of a separating outcome and a monopoly insurer, increasing the benefits of the public insurance system can improve the welfare of both high-risk and low-risk individuals.
} 


\section{Identical risk aversion}

Our model assumed that all individuals had identical levels of risk aversion. However, similar results would hold, for example, if individuals differed in risk aversion but not health risk. Rather than the Australian system leading to transfers from highillness-risk to low-illness-risk individuals it would lead to transfers from highly-riskaverse to less-risk-averse individuals. There would seem to be little merit in such a transfer which again moves income from those who are ex ante less well off (due to their high disutility of risk) to those who are ex ante better off. The system is still characterised by anti-insurance.

\section{Identical income levels}

Clearly the most controversial assumption made in our model is that we compare individuals with identical income levels. In this situation, the Australian health insurance system transfers income from those most likely to require health treatment to those less likely to require health treatment. But what if income levels differ? What if the poor cannot afford to purchase private health insurance so that they rely on the public insurance system? Don't they then receive a transfer from those high-income individuals who take out private health insurance?

The answer to this last question is simple. Yes! But this answer does not provide support for the current health insurance system. Rather, it highlights the inadequate level of insurance support for low-income individuals and the ludicrous nature of the existing transfers embedded in the Australian health insurance system.

If low-income individuals are unable to take out private insurance even if they have a high-risk of illness, then this reflects the devastating effect that the loss of income in the case of illness will have on these poorest individuals. The poor are unable to afford even actuarially fair insurance to protect themselves against adverse health events. But the existing partial insurance provided by the public insurance system is cold-comfort to these individuals. While the high-health-risk poor might receive an implicit tax subsidy if

The low-risk individuals gain a larger transfer from the high-risk individuals through the taxation system. But the high-risk individuals also gain utility because the public system is a more effective competitive threat to the private monopoly insurer. The private insurer has to offer the high-risk individuals a better 
they rely on public insurance, this insurance is inadequate. Those poor at the most risk are forced to rely on a level of insurance that is less than the health insurance gained by wealthier high-risk individuals. A system that provides inadequate (albeit subsidized) insurance to those who are poorest and least healthy, in our opinion, is not a system that should be applauded and defended. Rather, if the poor receive inadequate health insurance, then this strongly suggests that the existing system needs reforming.

The inadequate nature of the existing insurance system becomes even more obvious when we consider all the transfers. While the poor may receive an implicit subsidy from those richer individuals who have private health insurance, so too do the most healthy rich. Thus, the system provides the same subsidy to those most well off in society as it provides to the poorest in society. At best, the equity of taxing the sick rich to pay both the well rich and the poor is debatable.

The undesirable transfers that characterize the current mixed Australian system (that we have characterized as anti-insurance) hit every income cohort. Consider families who earn $\$ 30,000$ to $\$ 40,000$ per year. These families are not rich. But our analysis shows that those families most at risk in this income cohort implicitly transfer money to those least at risk. The elderly, those with young families or those with a family history of health problems transfer funds through the health insurance system to the young, single and healthy in that same income cohort. And the same holds for those families in the $\$ 40,000$ to $\$ 50,000$ income cohort, the $\$ 60,000$ to $\$ 70,000$ cohort and so on. While money might 'trickle down' the insurance system to the poor, in our opinion this is unlikely to offset the anti-insurance welfare loss placed on all individuals.

\section{Conclusion: reforming the Australian health insurance system}

Our analysis in this paper has highlighted the limitations and inadequacies of the existing Australian health insurance system. We have shown, using a simple standard model of insurance, that the Australian health insurance system creates a form of antiinsurance. In other words, the mixed public-private system results in income transfers that raise the risk facing an average individual. Further, these transfers have undesirable

insurance contract and the resultant welfare gain to high-risk individuals more than offsets the loss due to increased tax transfers. 
implications from an equity perspective. The health insurance system implicitly transfers funds from those least well off (in terms of health risk) to those most well off in society.

If the current system is inadequate, how should it be reformed? Our analysis also considered the existing 30 percent health insurance rebate, and showed that this rebate could help reduce the anti-insurance characteristics of the Australian system. However, the current ad valorem rebate also distorts the price of private health insurance. Thus, it reduces one distortion but at the cost of creating another distortion. We consider a lump sum rebate and show how this might be preferred to an ad valorem rebate.

In our opinion, however, more fundamental reform of health insurance in Australia is justified. The problem of anti-insurance is systemic in the joint duplication and supplemental nature of private insurance.

For example, Australia could remove the duplicative element of current private health insurance. The benefits of public insurance would be fully available to all individuals regardless of whether they have private insurance or not. This does not mean that the public insurance system would provide complete insurance. For example, it may continue to not cover ancillaries or private room accommodation. Insurance to cover the cost of these additional health expenditures would be provided by private firms. Such private insurance would be voluntary. If an individual wanted extra insurance cover on top of the public insurance system, they could buy this cover.

The welfare properties of supplementary insurance systems are well understood in economics (e.g. Finkelstein 2002). The supplementary insurance improves welfare by adding on to the public system and does not have the anti-insurance characteristics of the existing Australian system. Further, a supplemental insurance system could avoid the existing linking of insurance and service provision in Australia. There is no reason why a patient covered by public insurance should only receive care in a public hospital. Similarly, there is no reason why a public hospital should not be able to accept a patient with private supplemental insurance and provide some of the services covered by that insurance. In this sense, a move to supplemental private insurance could eliminate the (artificial) institutional divide in health service provision that exists in Australia.

A full analysis of supplemental private insurance or alternative system-wide reforms to Australian health insurance is beyond the scope of this paper. Rather, our 
paper has highlighted important welfare problems in the existing health insurance system. These problems have not been highlighted and formally analyzed previously and suggest that further research into the design of the Australian health insurance system is urgently required. 


\section{References}

Australian Institute of Health and Welfare (2002) Australian Hospital Statistics, 2000-01, AIHW Health Services Series, No.19., Canberra.

Barrett, G.F. and R. Conlon (2002), "Adverse Selection and the Decline in Private Health Insurance Coverage in Australia: 1989-1995," mimeo., UNSW.

Cutler, D. and R. Zeckhauser (2000) "The Anatomy of Health Insurance," Handbook of Health Economics, A.J. Culyer and J.P. Newhouse (eds), North-Holland: Amsterdam, pp.563-643.

Duckett, S. and T. Jackson (2000), "The New Health Insurance Rebate: An Inefficient Way of Assisting Public Hospitals," Medical Journal of Australia, 72, 439-442.

Finkelstein, A. (2002), "When Can Partial Public Insurance Produce Pareto Improvements?" Working Paper, No.9035, NBER.

Hirshleifer, J. and J.G. Riley (1992), The Analytics of Uncertainty and Information, Cambridge University Press: Cambridge.

Hurley, J., R. Vaithianathan, T.F. Crossley and D. Cobb-Clark (2002), "Parallel Private Health Insurance in Australia: A Cautionary Tale and Lessons for Canada," Discussion Paper, No.48, CEPR/ANU.

Jack, W. (1998), "Intergenerational Risk Sharing and Health Insurance Financing," Economic Record, 74 (225), pp.158-161.

Jost, T.S. (2001) "Private or public approaches to insuring the uninsured: lessons from international experience," New York University Law Review, 76, 419-492.

Rothschild, M. and J.E. Stiglitz (1976), "Equilibrium in Competitive Insurance Markets: An Essay on the Economics of Imperfect Information," Quarterly Journal of Economics, 629-49.

Smith, J. (2001) "How fair is health spending: the distribution of tax subsidies for health in Australia", Discussion Paper, No. 43, The Australia Institute.

Vaithianathan, R. (2000), "An Economic Analysis of the Private Health Insurance Incentives Act (1998)," Discussion Paper, No.427, CEPR/ANU.

Vaithianathan, R. (2002), "Will Subsidising Private Health Insurance Help the Public System?" Economic Record, 78 (242), pp.277-283.

Wilson, C. (1977), "A Model of Insurance Markets with Incomplete Information," Journal of Economic Theory, 16, pp.167-207. 
Figure 1: Separating Equilibrium With Private Insurance

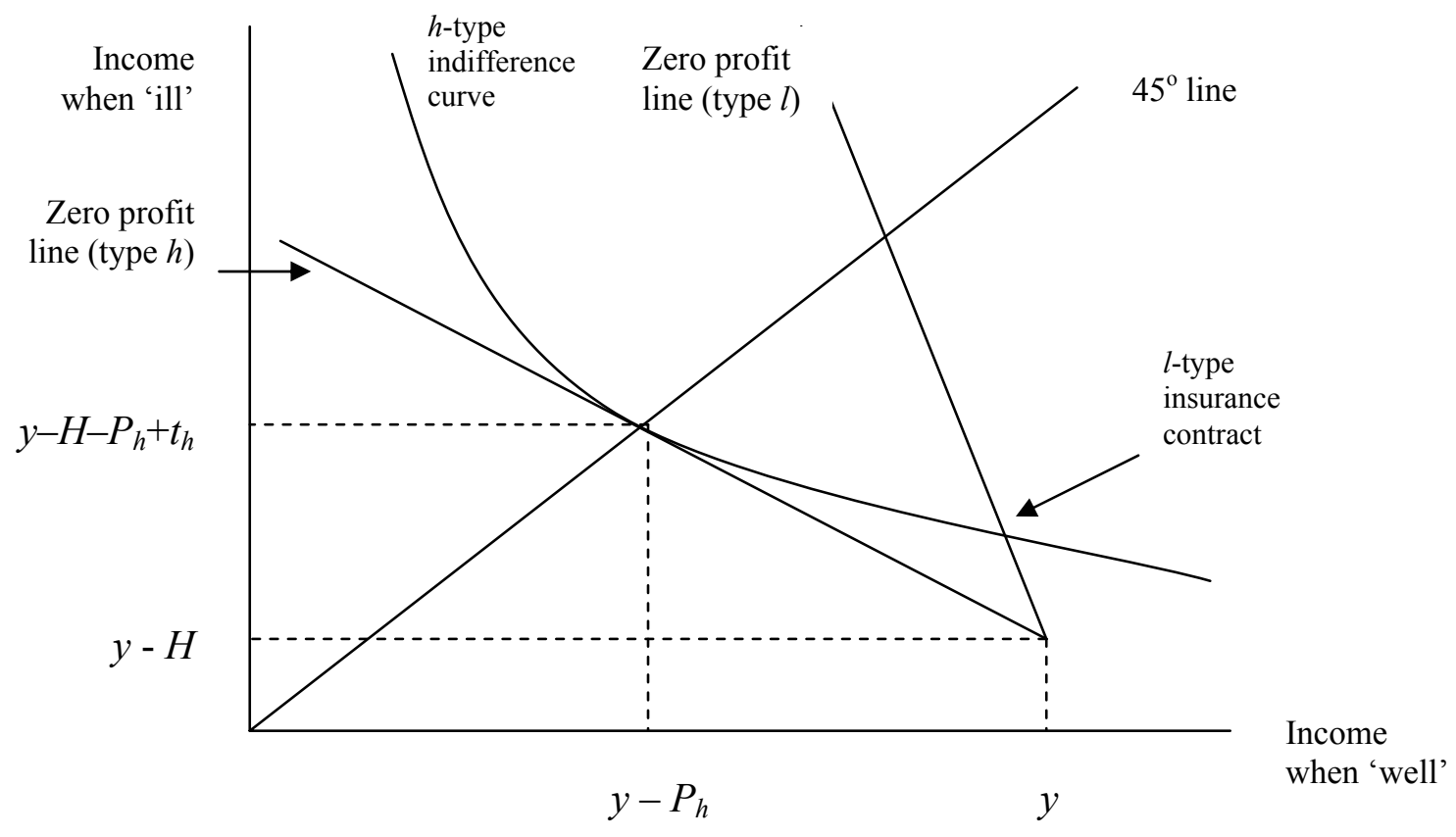

Figure 2: Pure Public Insurance

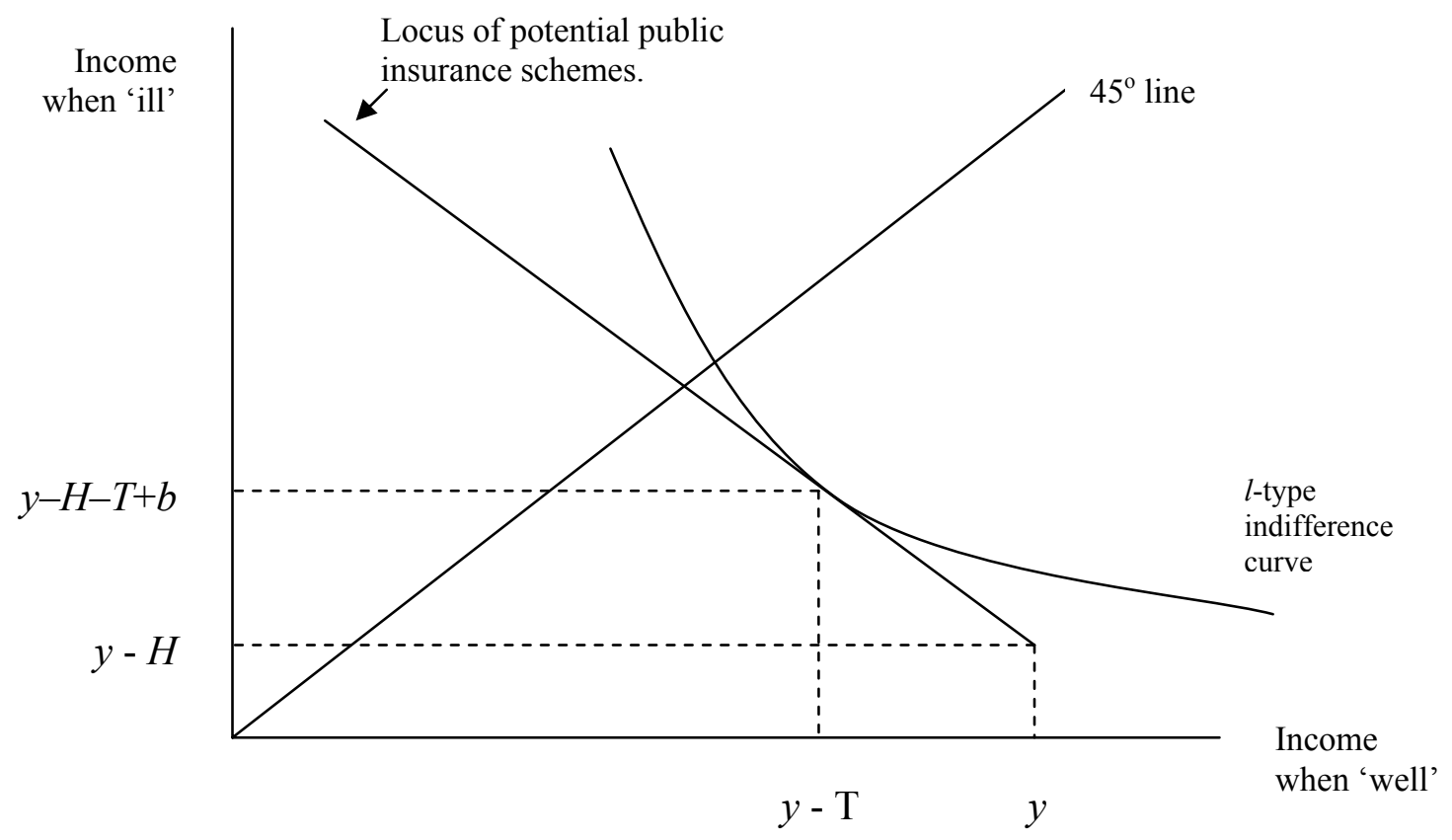


Figure 3 - No take-up of public insurance

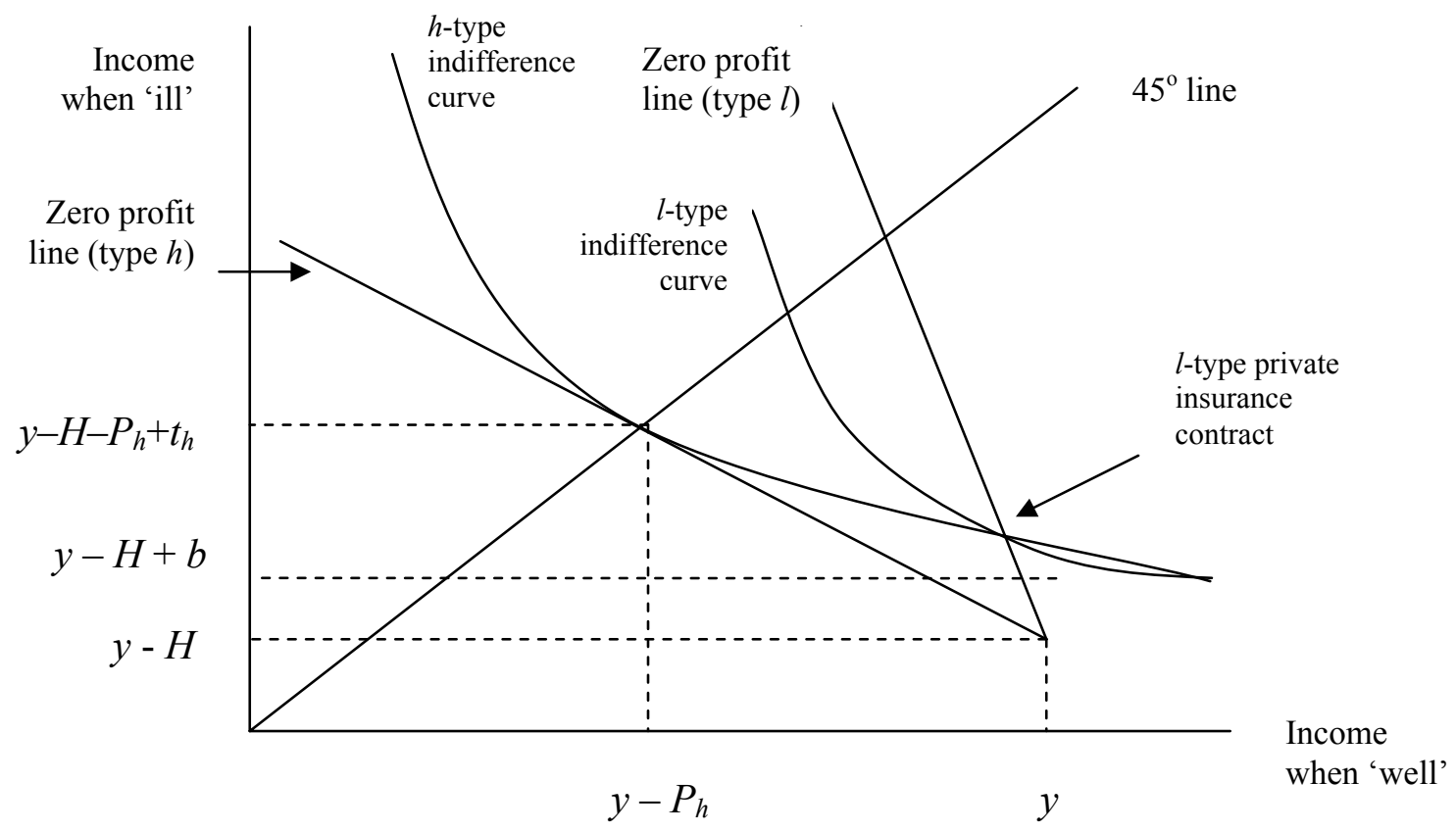

Figure 4: Separating Public-Private Equilibrium

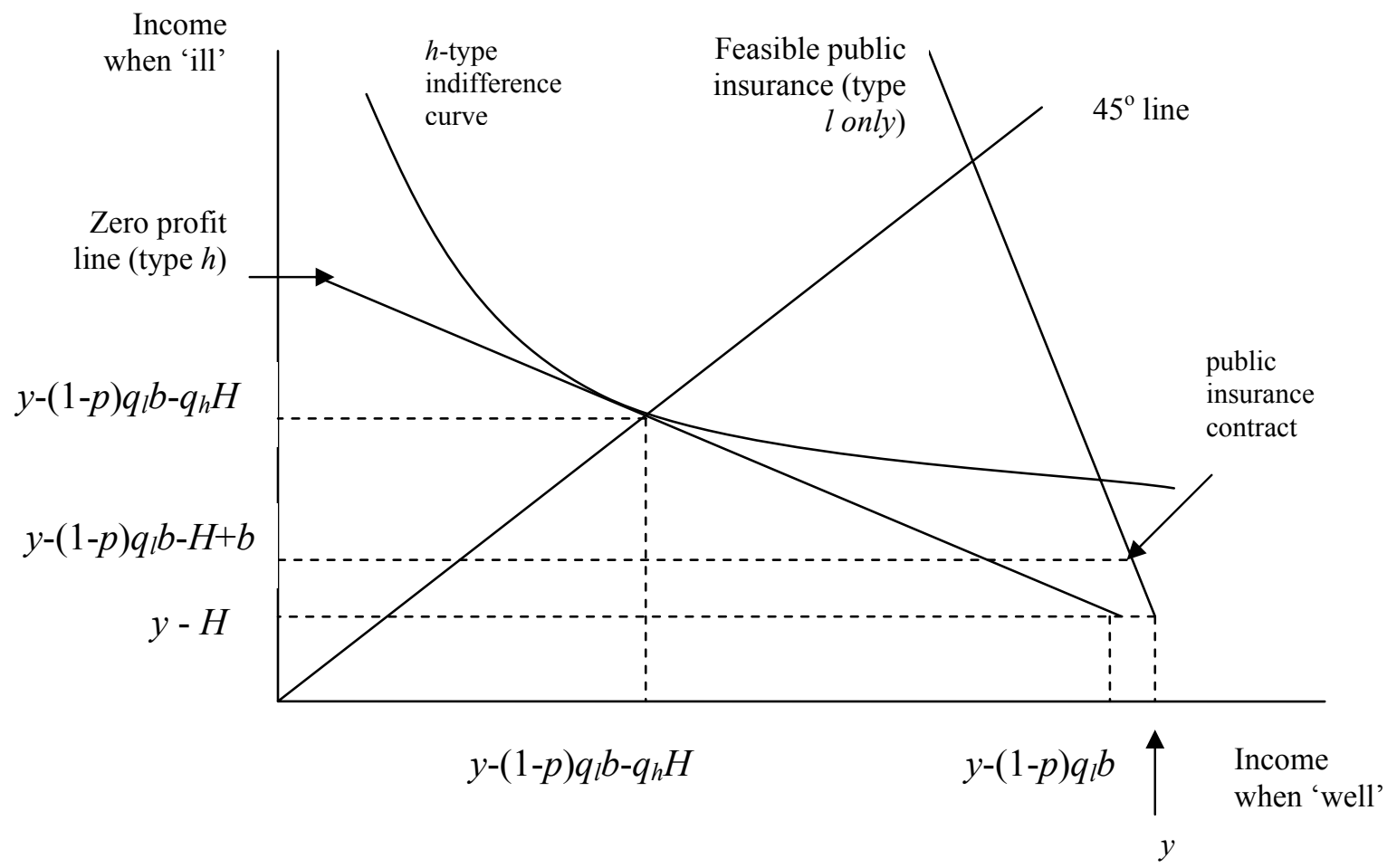

